QIOWADOT

\title{
Applied Construction Geology to Maximize Pavement Performance
}

Adriana R. Schnoebelen, Geologist 


\section{STRATIGRAPHY}

- lowa has a nearly complete sequence of Paleozoic strata.

- Regional Dip $3^{\circ}$ dip NE - SW:

Cambrian bedrock outcrops in

NE lowa, progressively younger

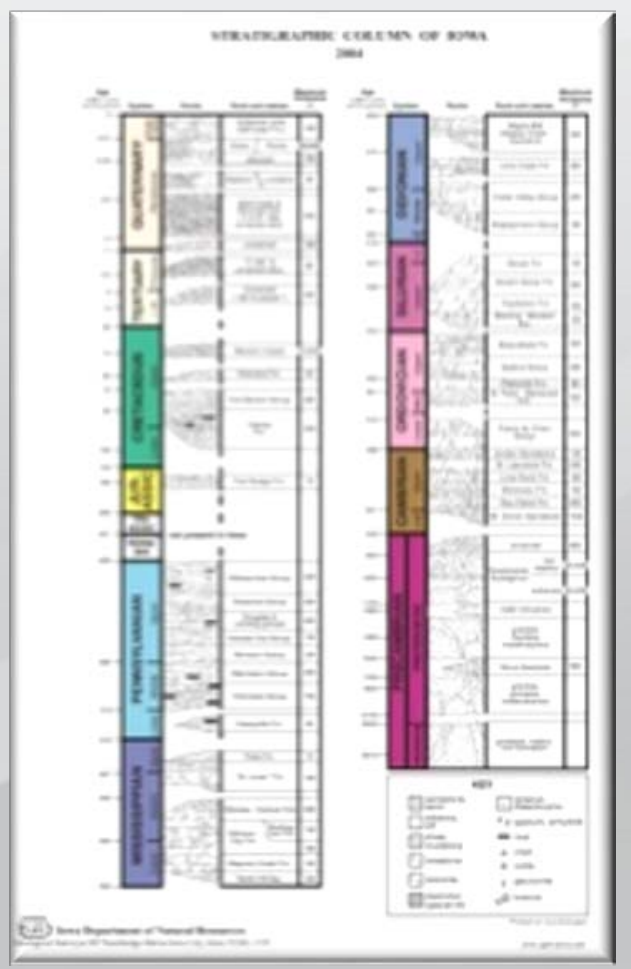
to SW lowa where Pennsylvanian bedrock outcrops.

- Glacial deposits overlay the bedrock.

- Generically termed 'Gravels'.

- Thickest in Northwest lowa

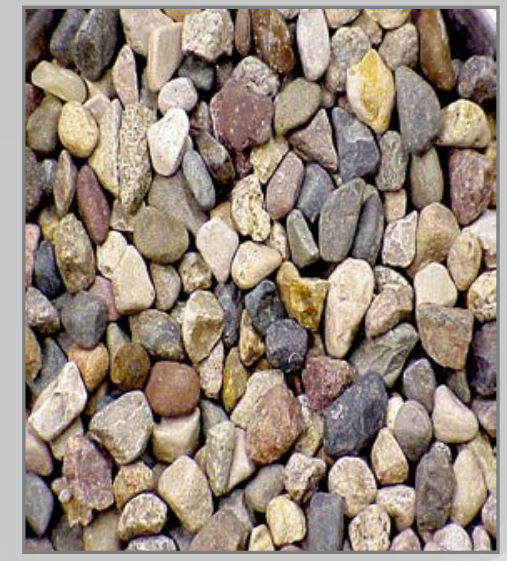




\section{BEDROCK GEOLOGIC MAP OF IOWA 1998}

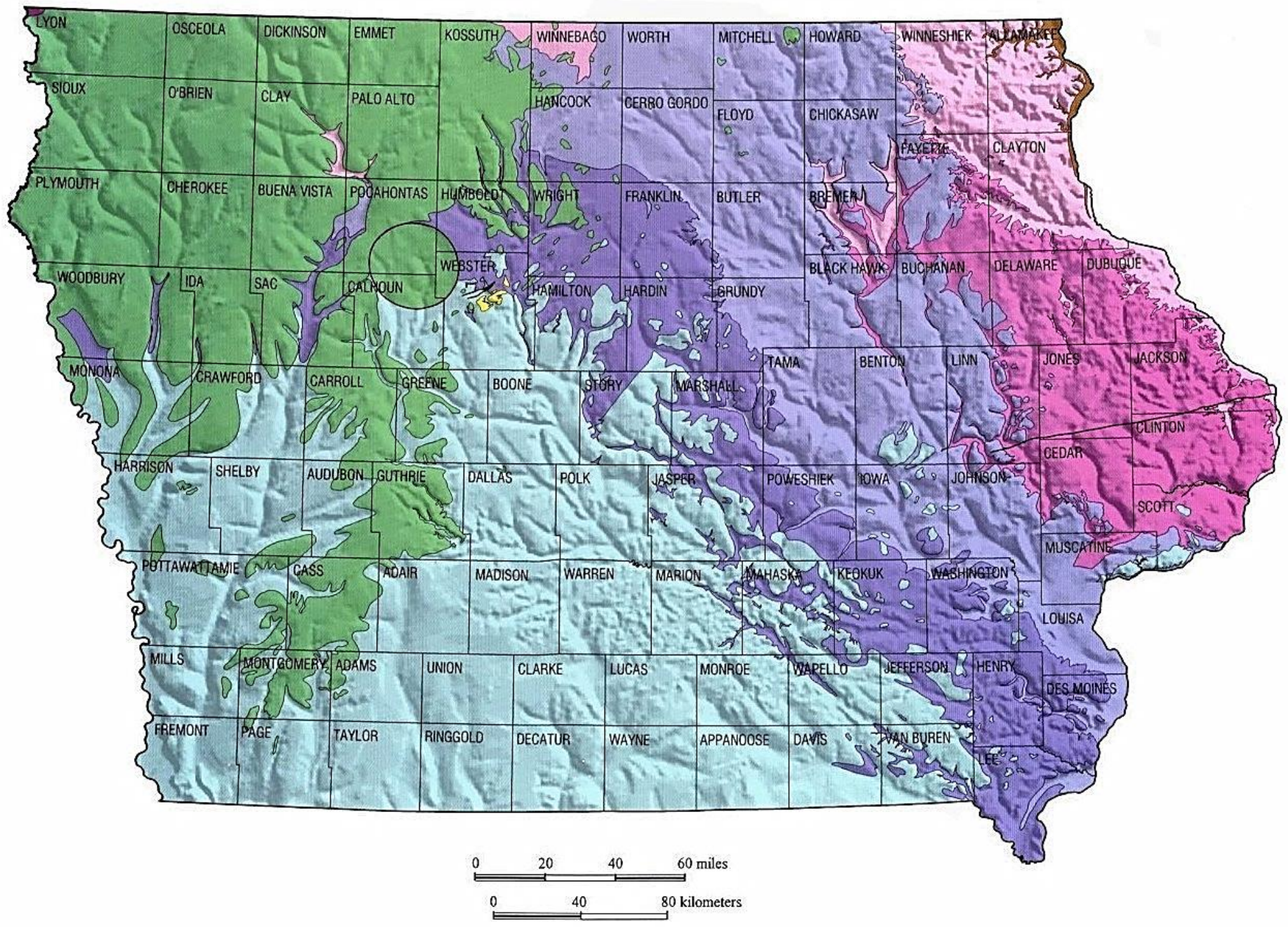

Image courtesy of Ray Anderson, Iowa Geological Survey 


\section{INDUSTRY}
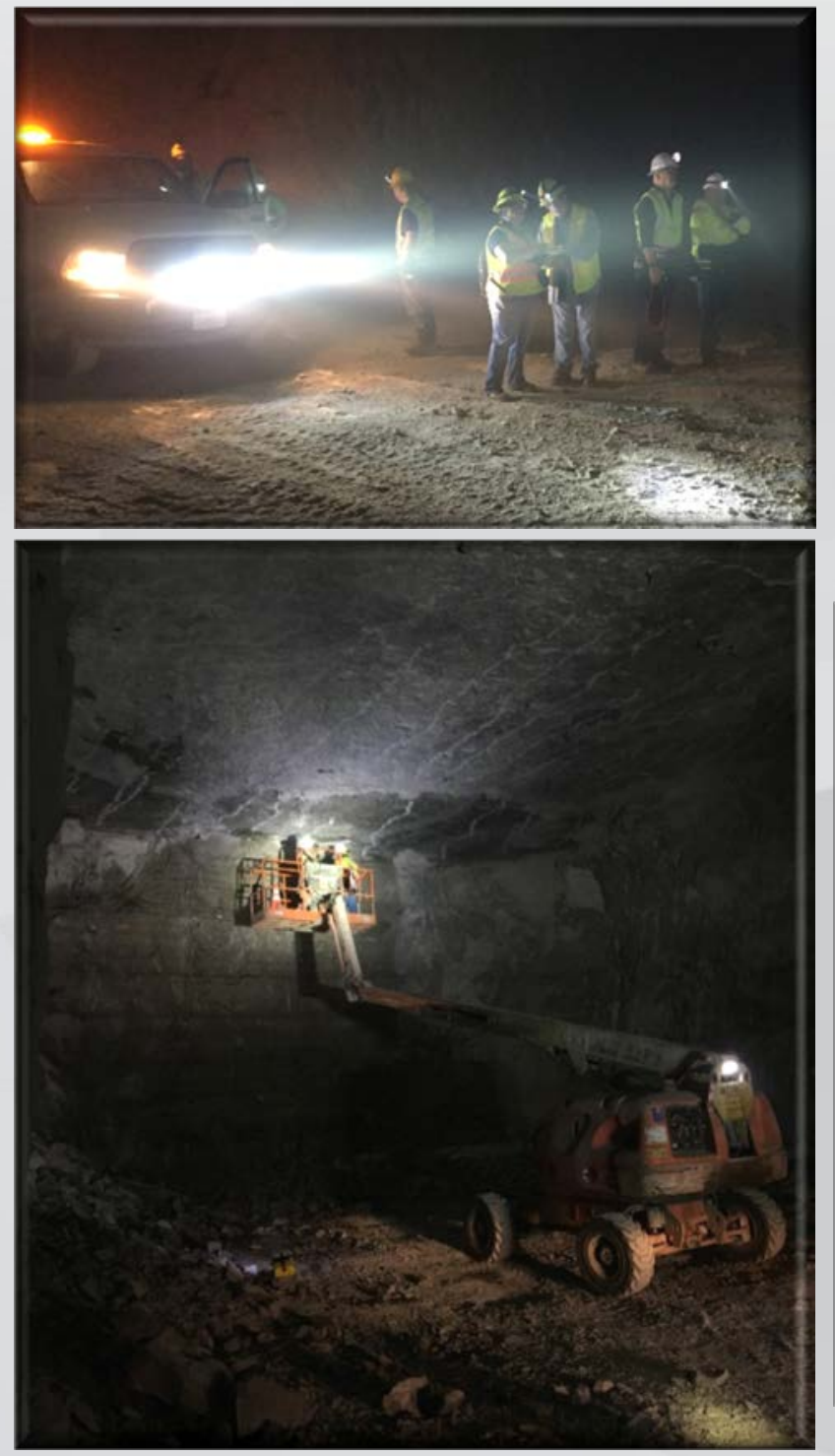

- Nearly 1000 active sources, in and around lowa. See IM T203

- Provide geologic sections for active sources

- Assist aggregate producers with ledge control

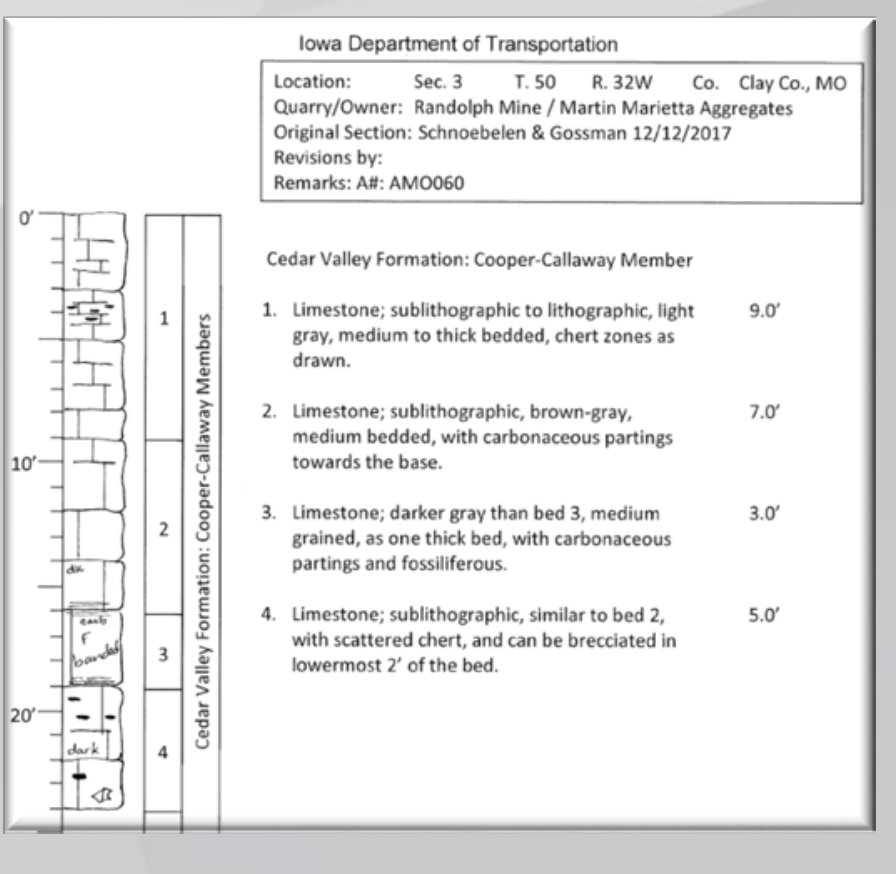

- Partner specifications with Industry. 


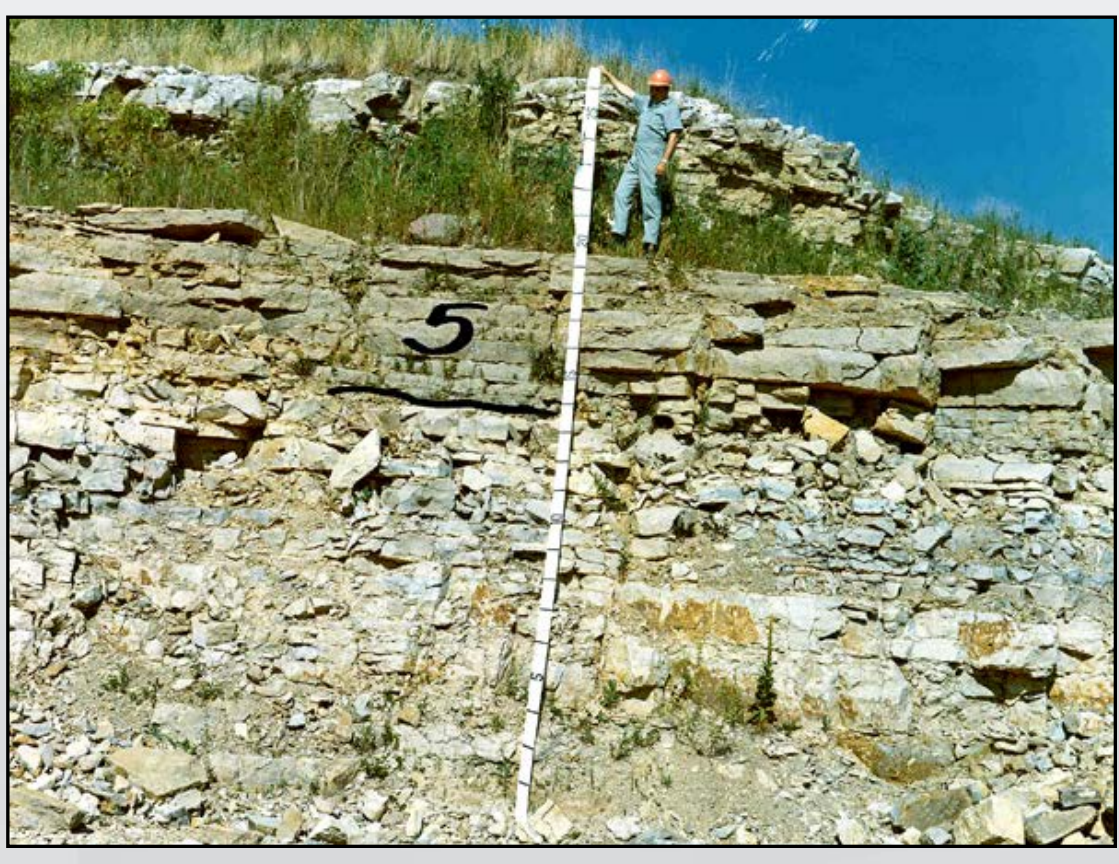

Southwest lowa

VARIABILITY

OF QUARRY

LEDGES

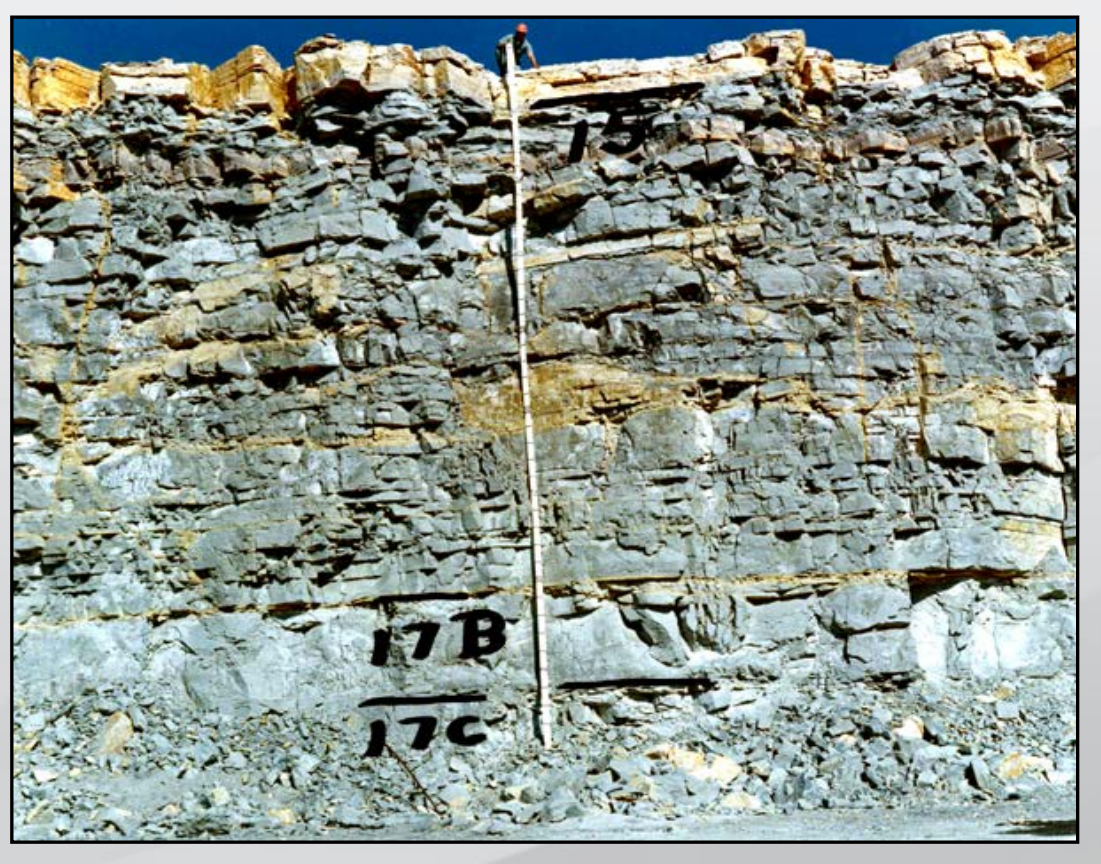

Northcentral lowa

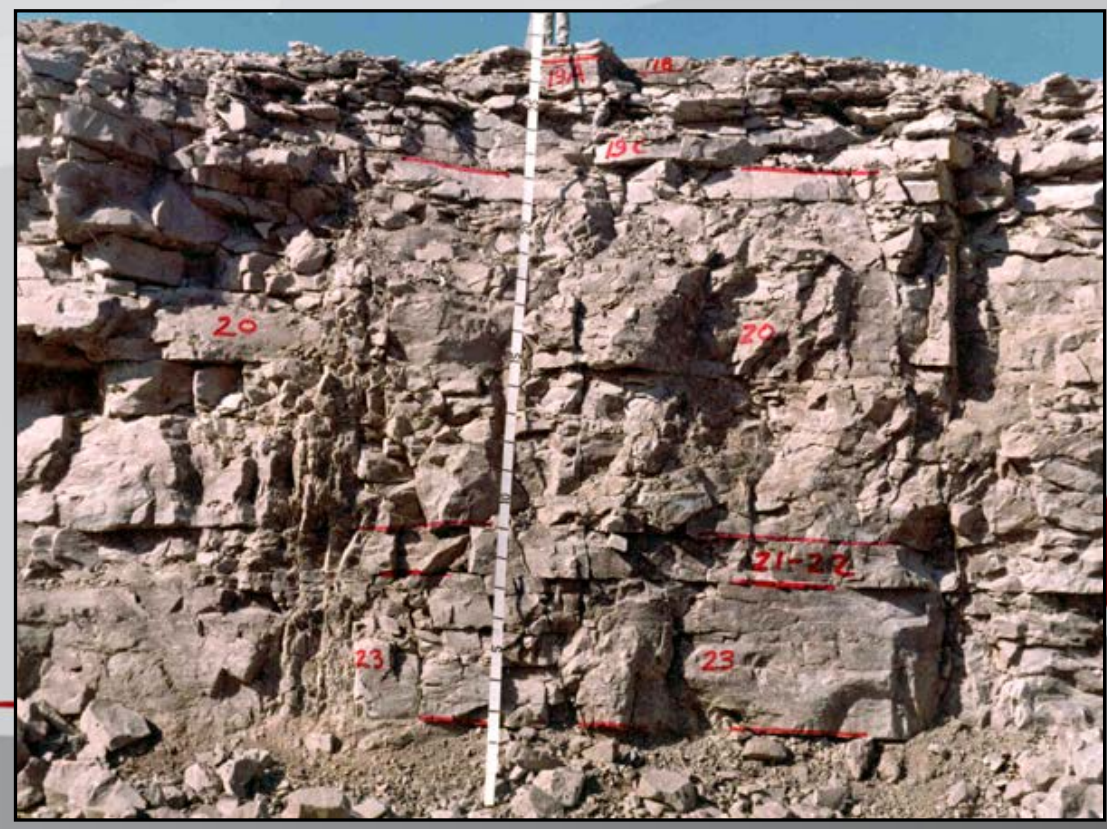

Western lowa 


\section{East Central}

lowa
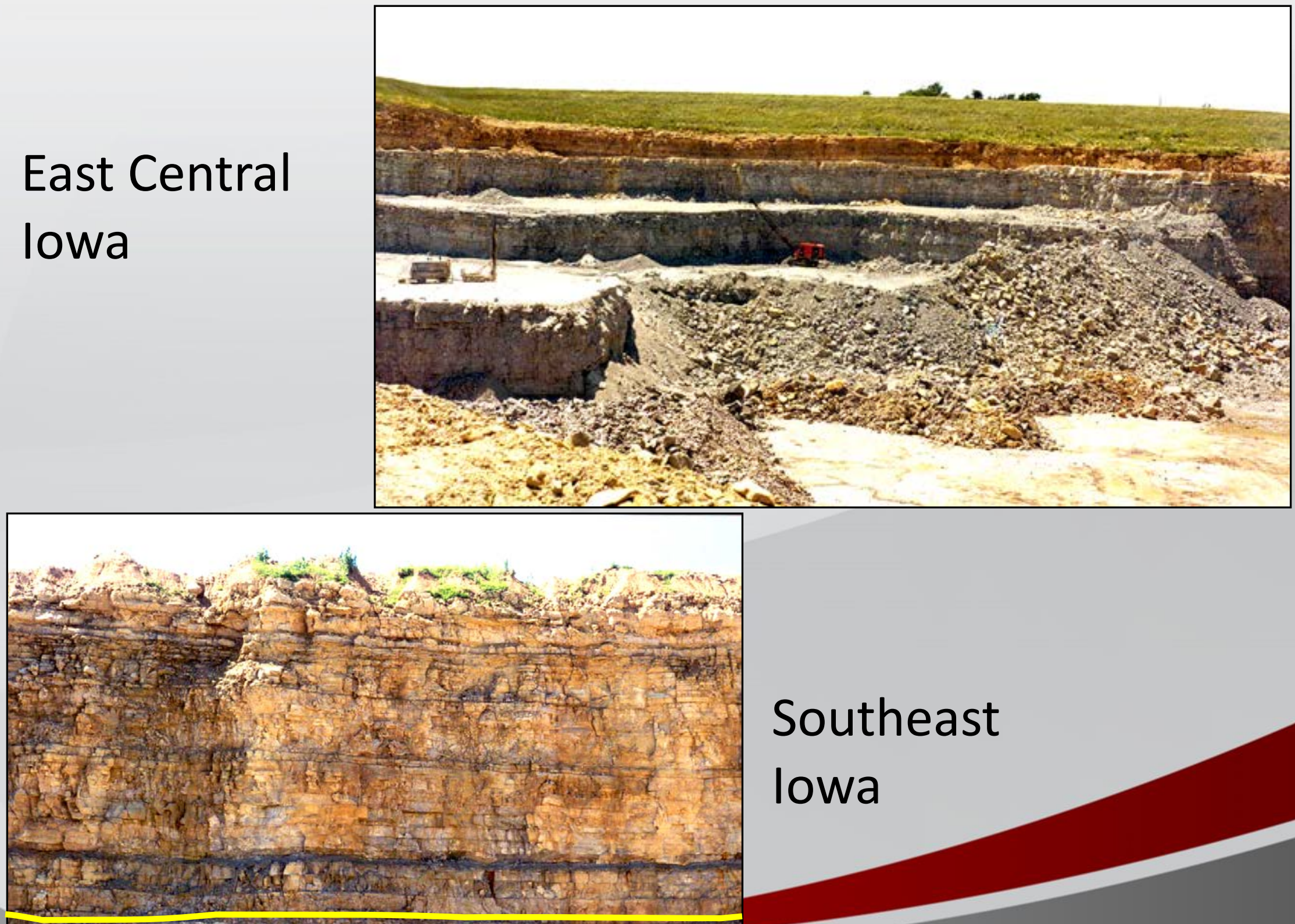

\section{Southeast}

lowa

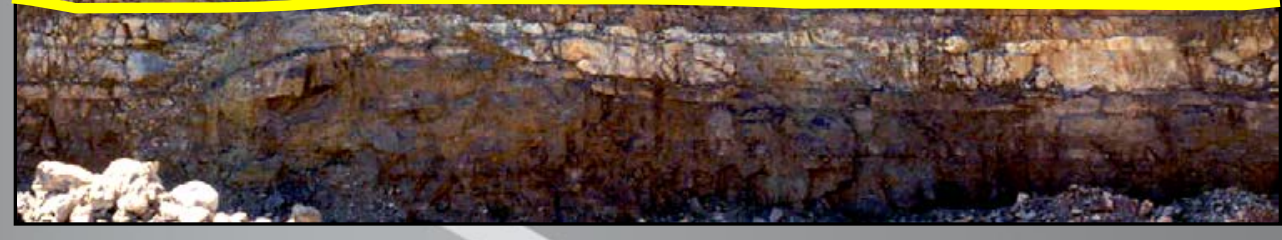




\section{Glacial “Gravel” Deposit}

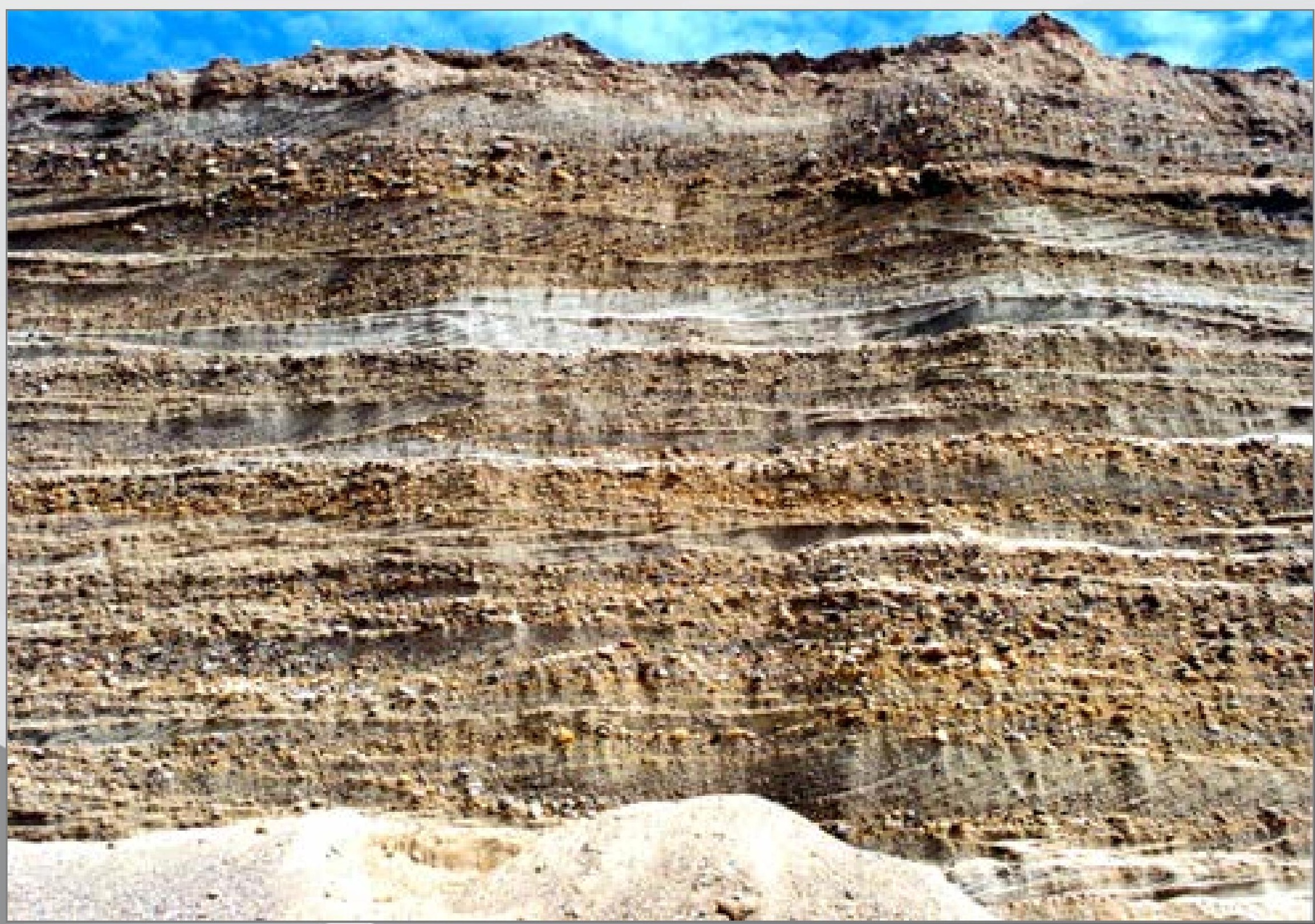




\section{DETERMINE DURABILITY CLASSES}

FOR PORTLAND CEMENT CONCRETE (PCC) AGGREGATES

USING SALT-SUSCEPTIBILITY QUALITY NUMBER AND PCC PAVEMENT SERVICE HISTORY 


\section{BACKGROUND}

- Pavement failures in the mid 1980's led former DOT geologist Wendell Dubberke to:

- investigate the causes for these failures (high DF)

- develop an algorithm that combined the pore index with aggregate chemistry to predict durability class.

- Algorithm was cross referenced to known pavement performance

- In 2000, the DOT began using SSQN as a concrete stone approval specification.

- After 10 years evaluation, current DOFgeologist Bob Dawson made revisions to the algorithm. 


\section{IOWA DOT DURABILITY CLASSES}

3 Classes: $2,3,3 i$

- Class 2-minimal deterioration only after 20 years, non-interstate usage

- Class 3-minimal deterioration only after 25 years, non-interstate usage

- Class 3i-minimal deterioration only after 30 years, interstate usage 


\section{PRINCIPLE REASONS FOR AgGREGATE}

FAILURE

- Clay content

- Pore system

- Capillary pores yield many available sites for chemical reactions from deicing salts to occur

- Poor freeze thaw performance

- Chemistry of the Aggregates

- Stability of minerals that form the aggregate.

- Unstable due to substitutions in the crystal lattice

- Fe for $\mathrm{Mg}$ in $\mathrm{CaMg}\left(\mathrm{CO}_{3}\right)_{2}$ 


\section{THESE THREE FACTORS ARE EVALUATED}

BY:

- Measuring the clay content of the aggregate (XRF, alumina quality number).

- Determining the pore system for pore size and volume (lowa Pore Index quality number).

- Examining the limestone and dolomite fractions for chemistry and mineralogy (XRF/XRD quality number). 


\section{IOWA PORE INDEX NUMBER}

- This number quantifies the amount of water an aggregate particle absorbs into it's pore system.

- The Pore System comprised of:

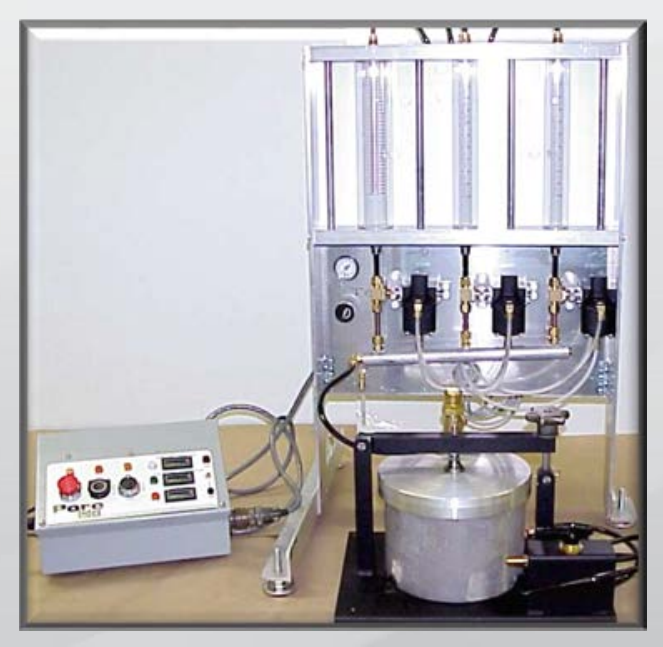
Primary-large pores Secondary-small, capillary pores

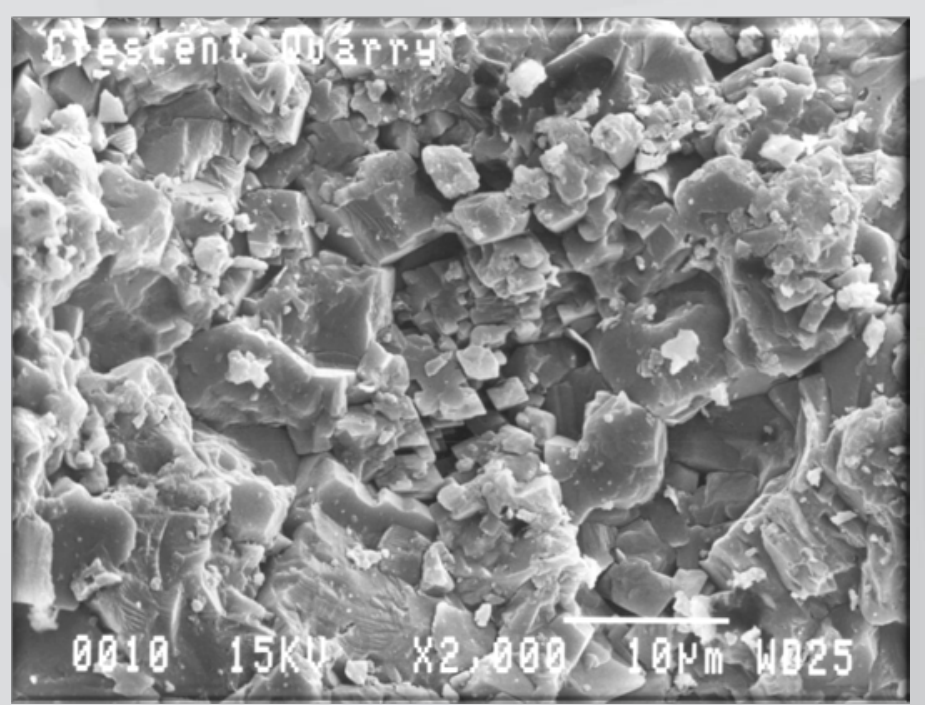

SEM Image on left (5000X); grain size of a poor performing aggregate. SEM Image on right (90x); grain size of a good performing aggregate.

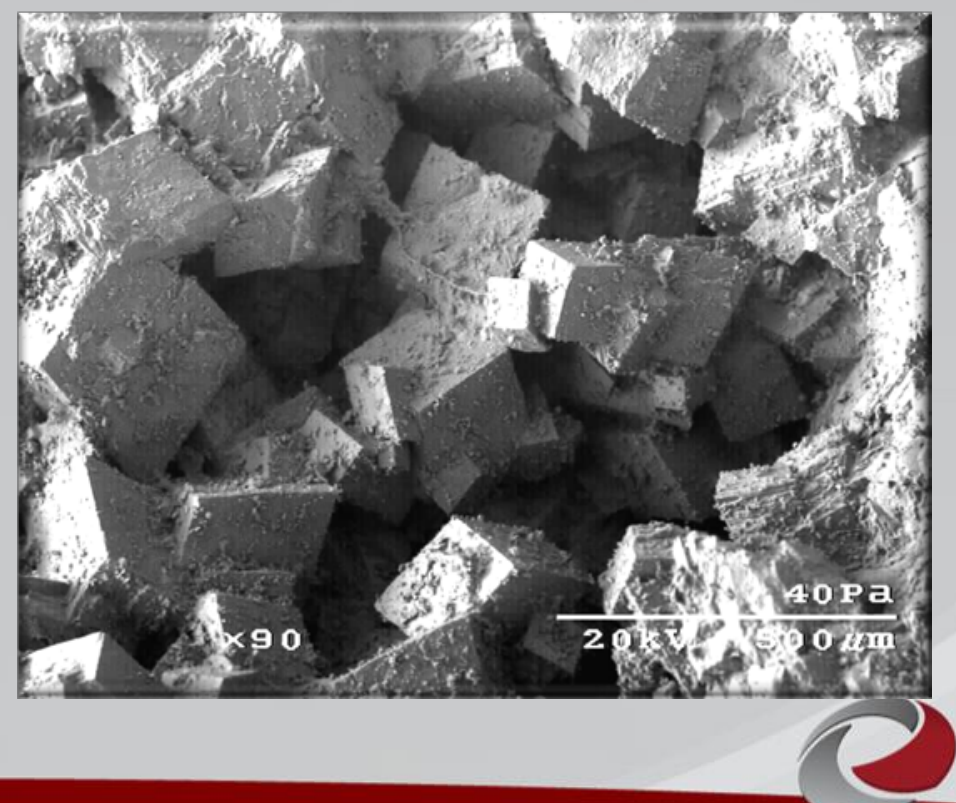




\section{OVERALL SALT-SUSCEPTIBILITY QUALITY NUMBER}

\section{Overall Quality Number}

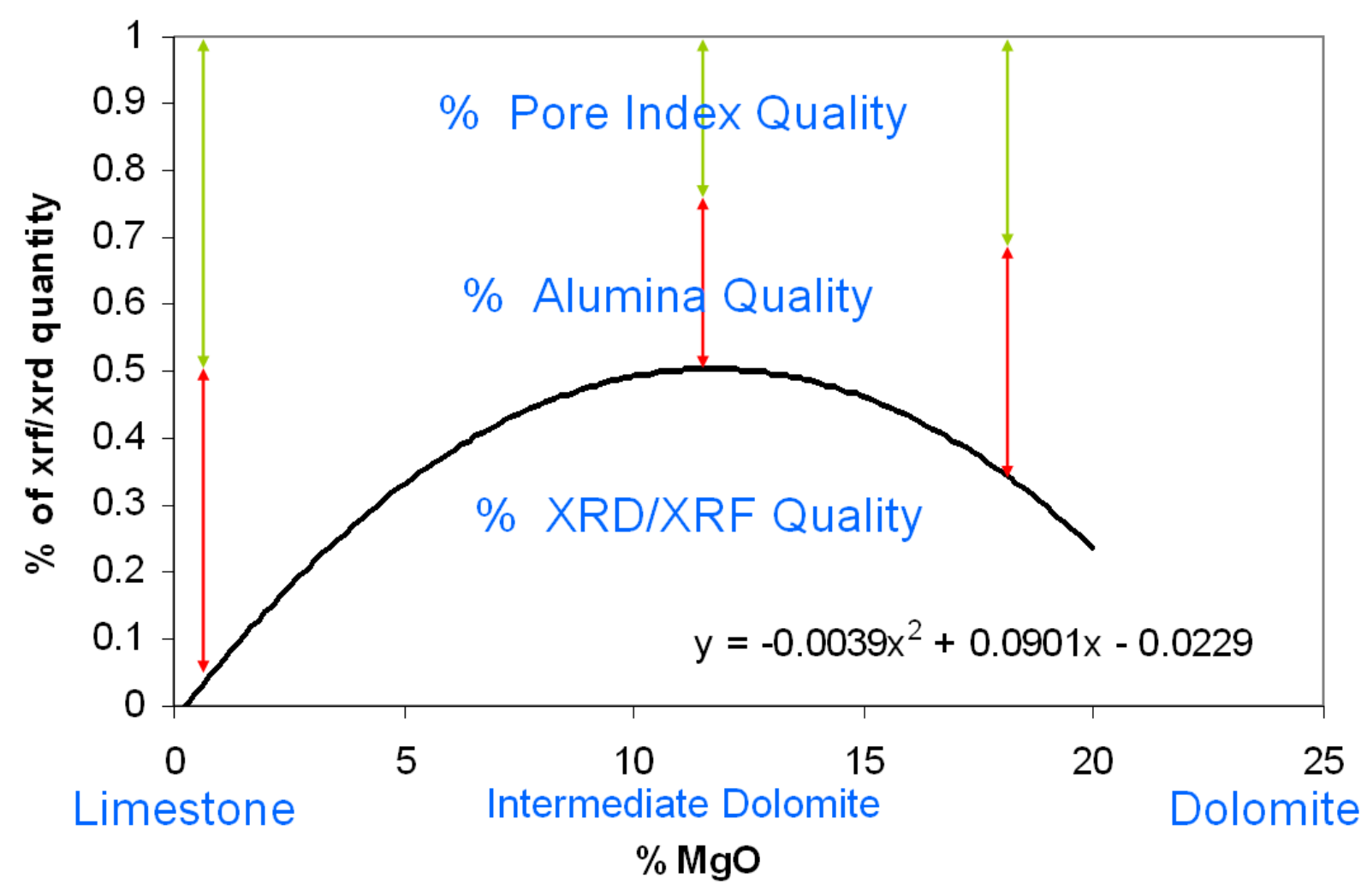

Graphical representation and equation showing the proportional fraction that the XRF-XRD quality number has in the salt-susceptibility quality number based on how dolomitic the aggregate is. 


\section{StATES WhERE IOWA DOT Testing}

METHODS ARE USED OR HAVE BEEN USED.

IOWA PORE INDEX TEST

(AASHTO TP120-16)

- Kentucky

- Michigan

- Minnesota

- Missouri

- Montana

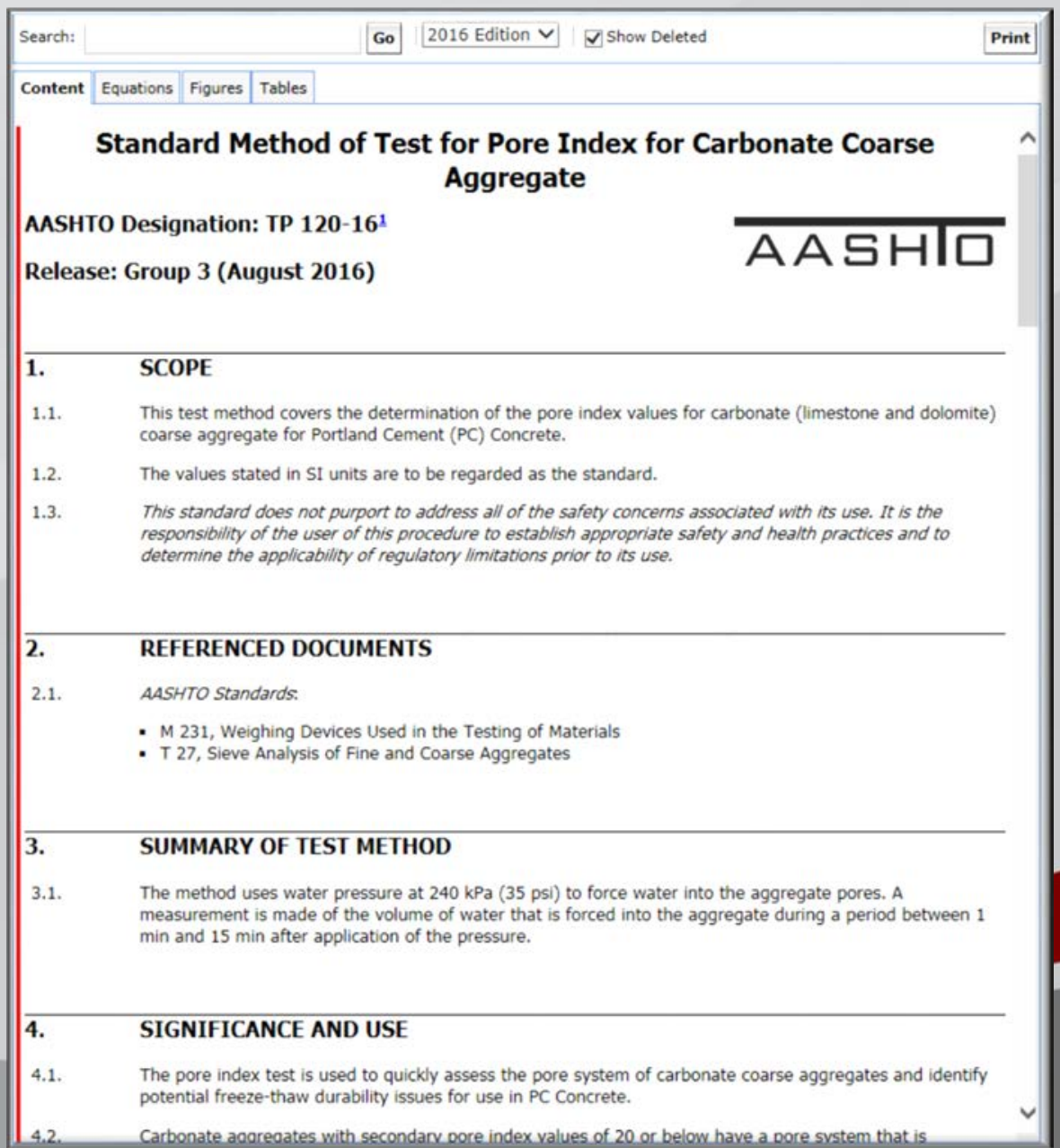

XRF (ALUMINA)

EVALUATION

- Missouri

- Florida

- Michigan 
A RECENT FHWA NATIONWIDE REVIEW OF STATE DOT'S, RECOGNIZED THE IOWA DOT FOR HAVING THE BEST SYSTEM FOR DETERMINING THE QUALITY OF AGGREGATES USED IN CONSTRUCTION PROJECTS.

We're the ONLY StATE IN THE NATION that ADDRESSES SALT-SUSCEPTIBILITY IN CONSTRUCTION AGGREGATES. 
FORENSICS FOR

PAVEMENT

SERVICE

HISTORY
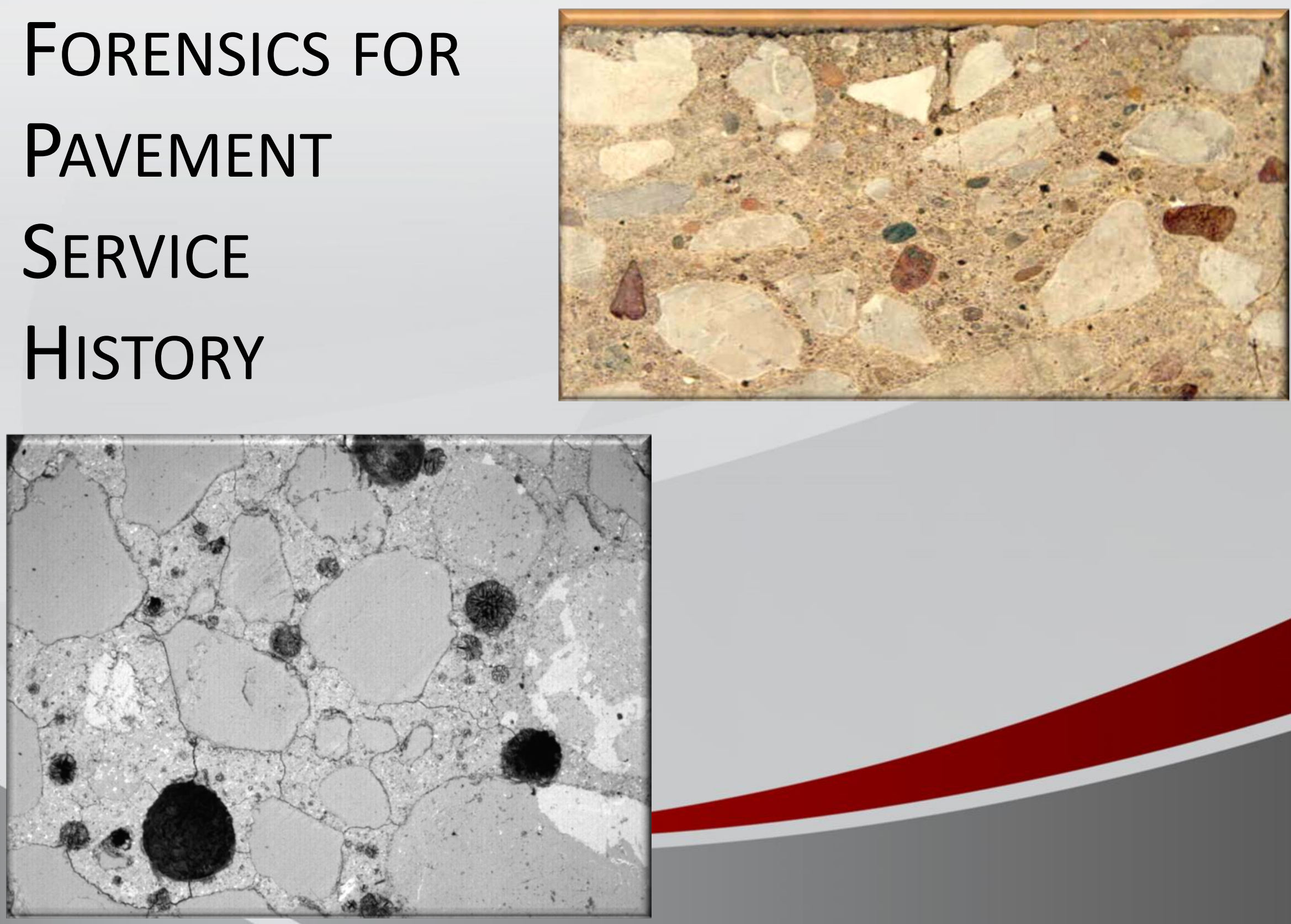
Extremely D-cracked pavement from Saltsusceptible Aggregate

US Hwy 30 Carroll County, $30+$ years with no aggregate related deterioration 

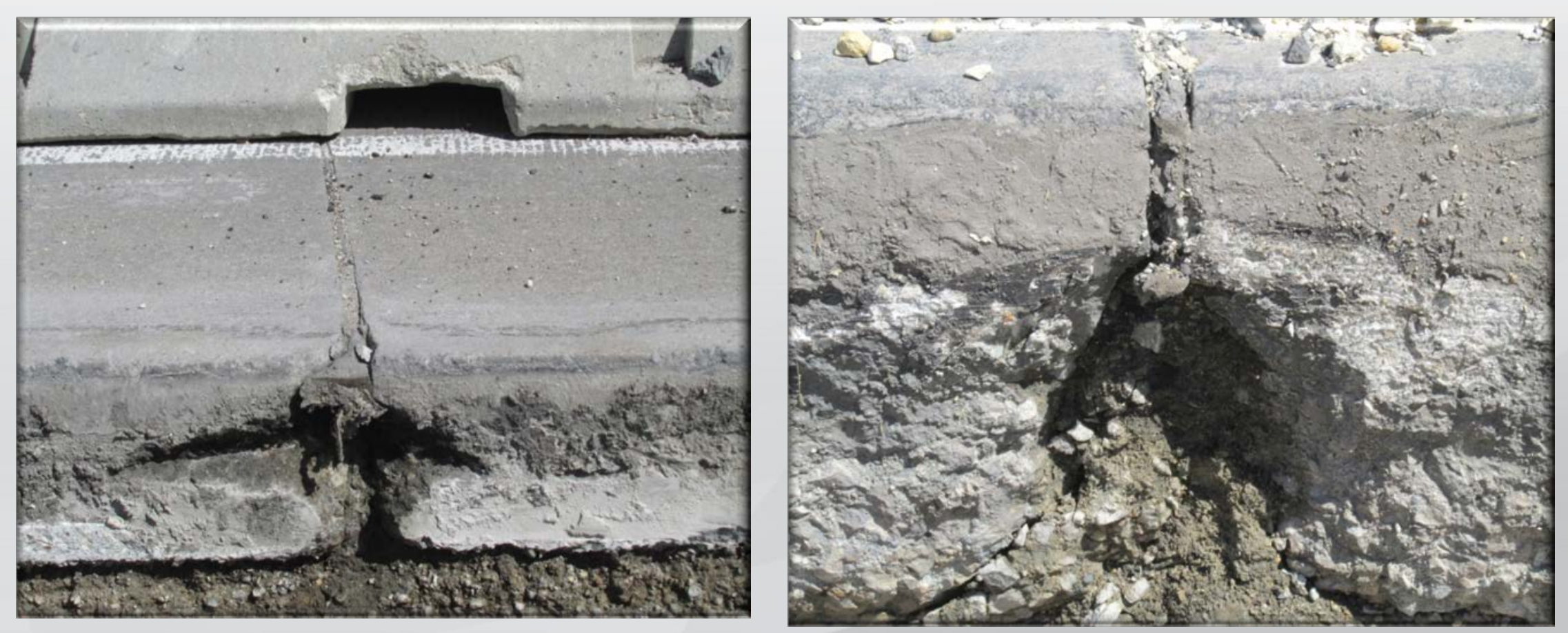

Side views from a recent pavement evaluation showing what $\mathrm{D}$-cracking looks like below the pavement surface. 


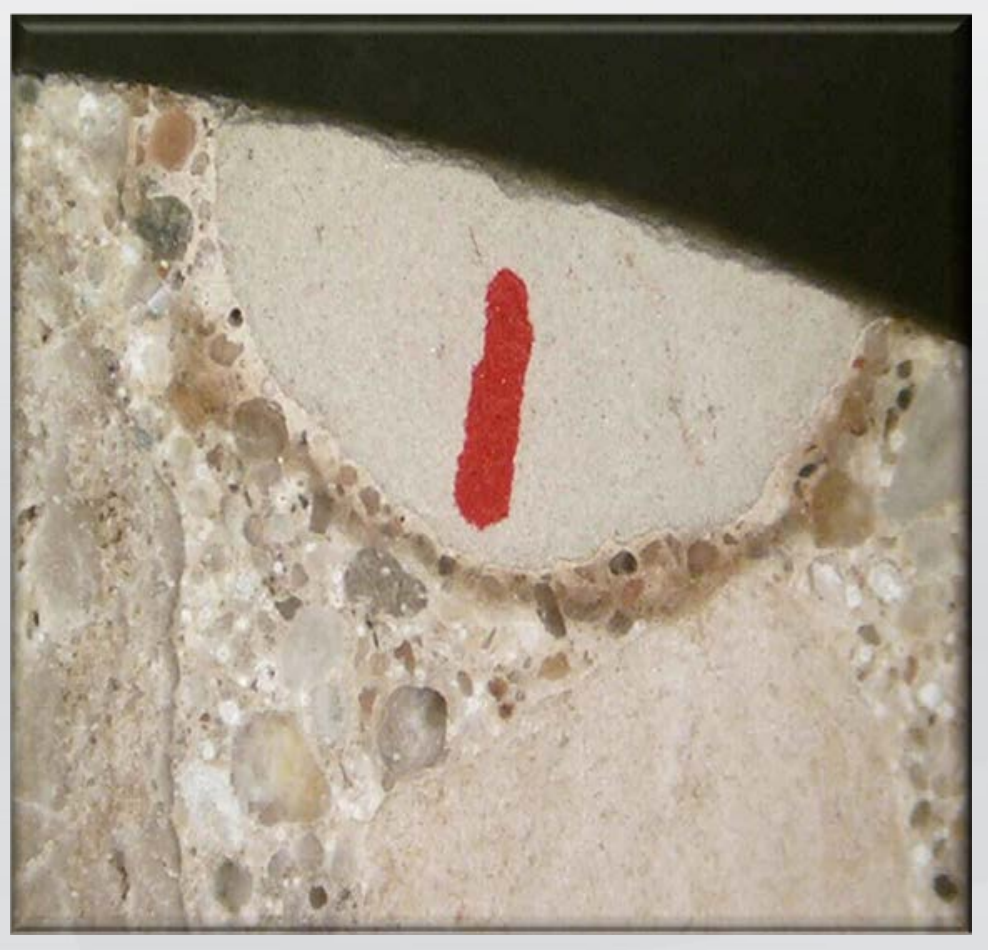

Staining in the cement paste. ACR?
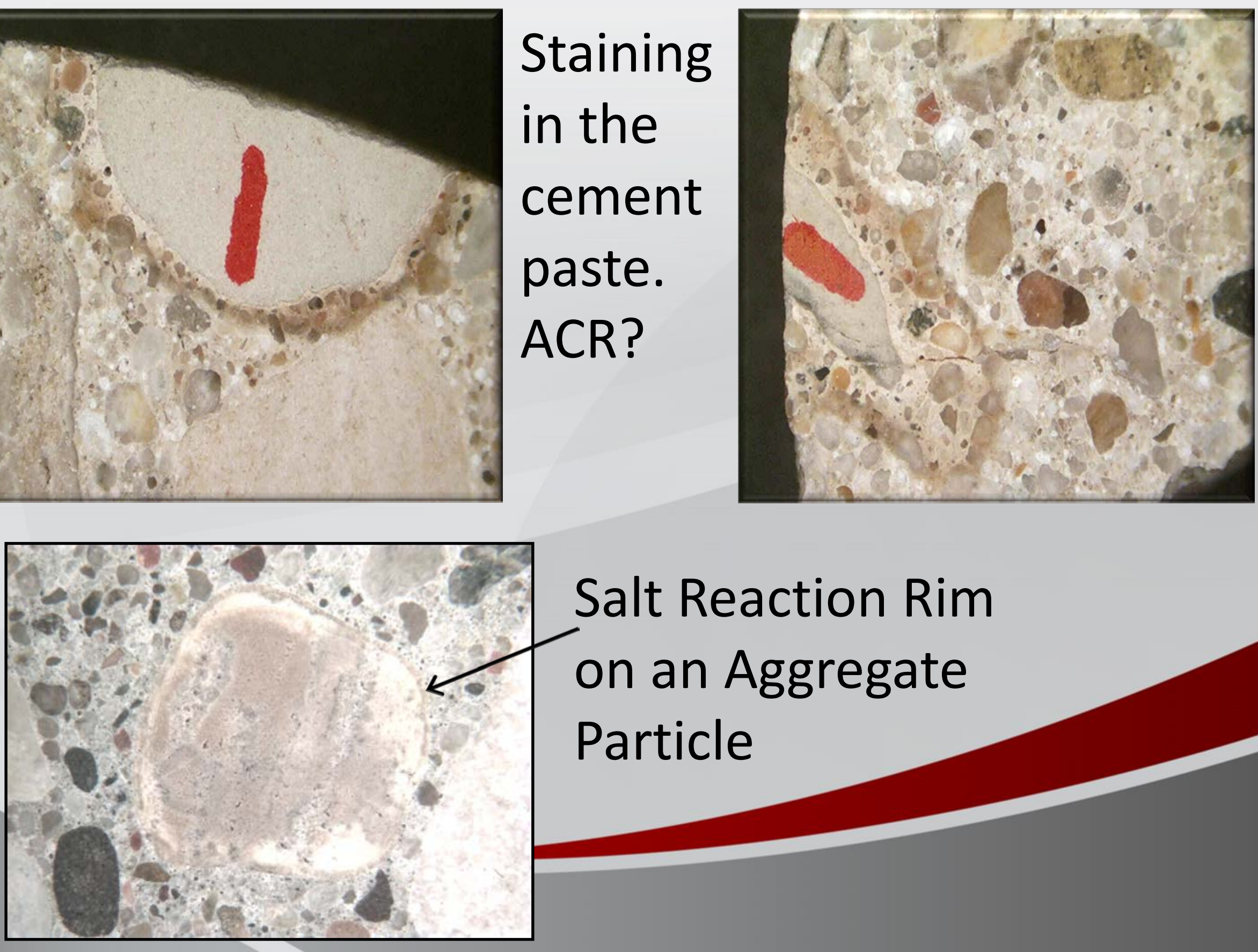
WHY IS AGGREGATE IMPORTANT?

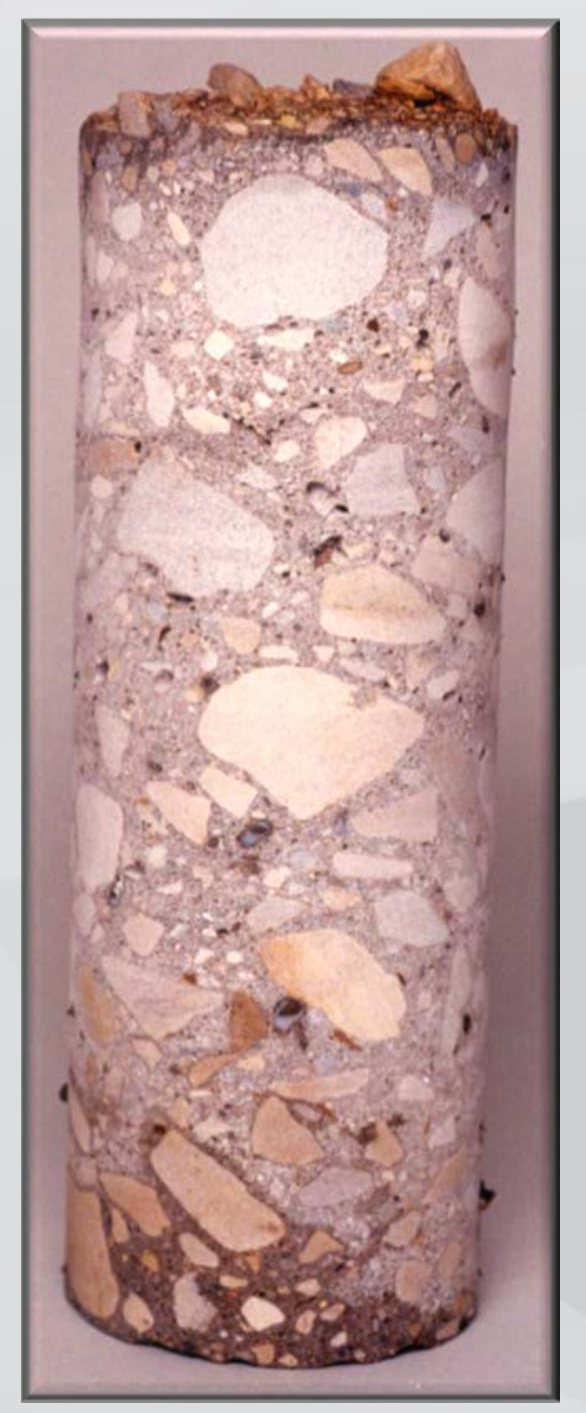

\author{
It's the \\ primary
}

component

of PCC, HMA, and granular

surfacing

materials.
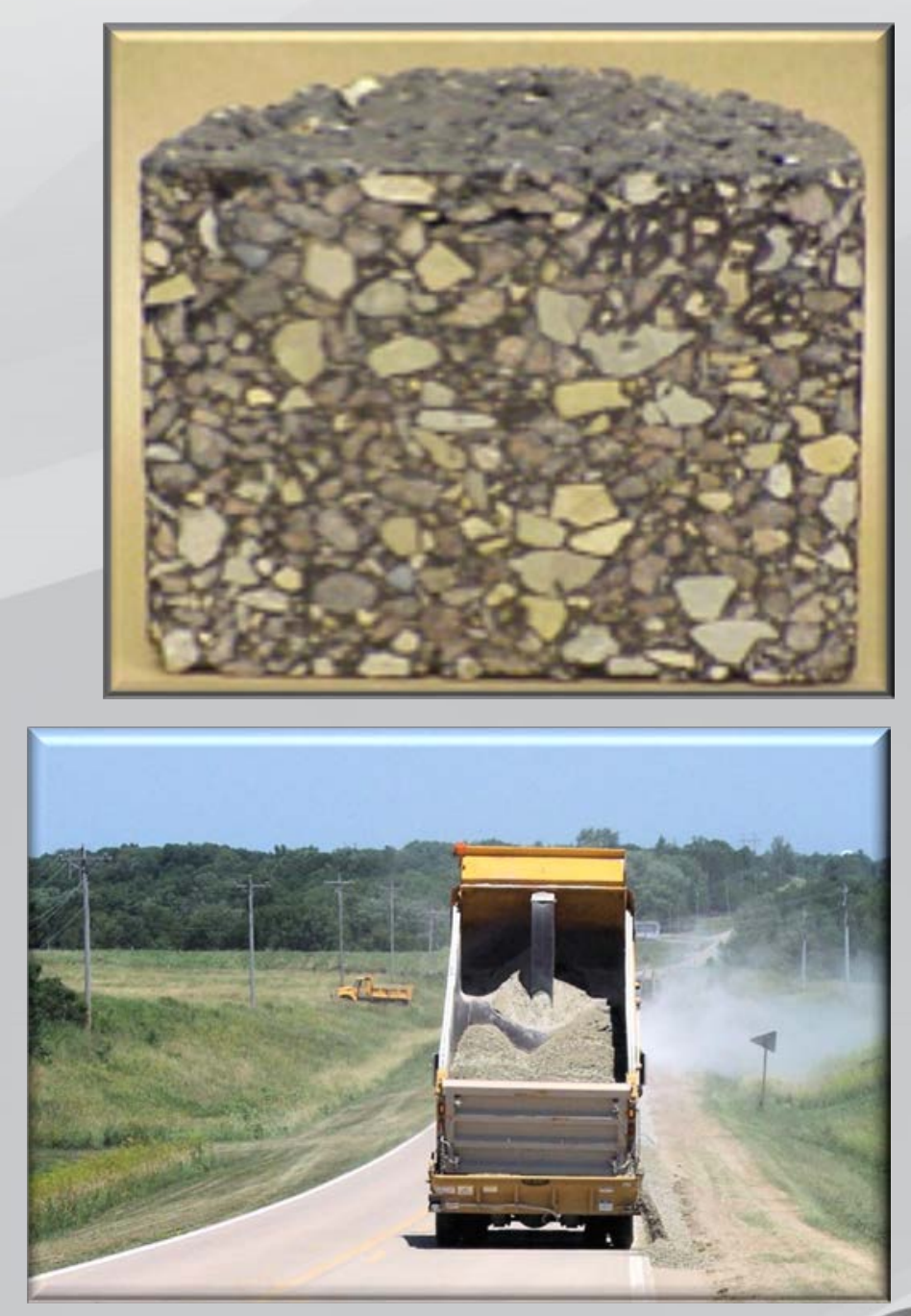


\section{PROJECT}

\section{EXAMPLE}

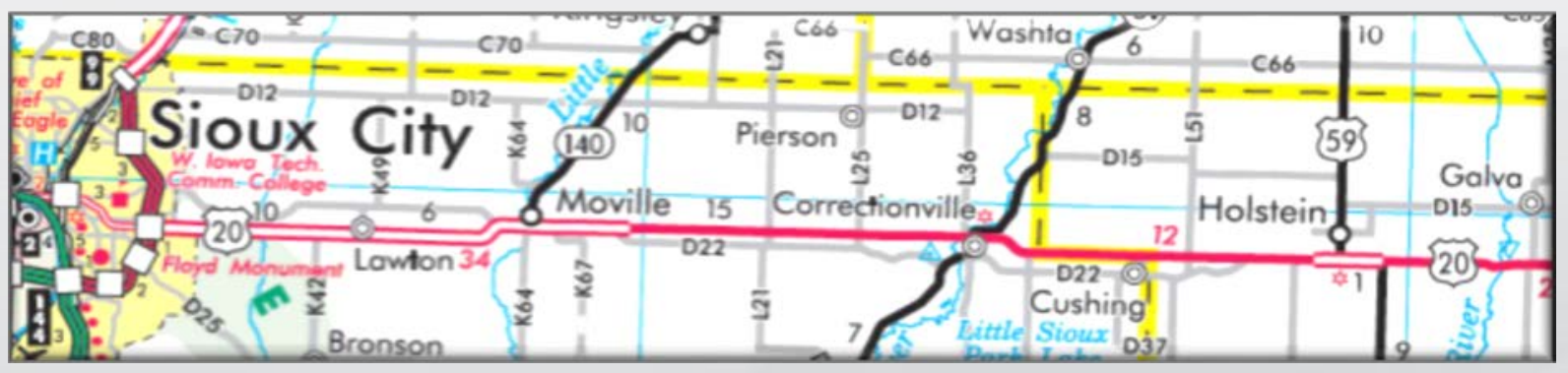

US Hwy 20 from Moville to Galva - Approx. 24 miles

550,000 Total Tons of Aggregate used in 2016

- 25,000 Tons of Floodable Backfill

- 150,000 Tons of Granular Subbase

- 100,000 Tons of Granular Backfill

- 100,000 Tons of Special Backfill

- 70,000 Tons of 1" PCC Rock

- 70,000 Tons of Sand for PCC

- 15,000 Tons of Intermediate PCC

- 20,000 Tons of Reclaimed/Recycled Aggregate
Based on current production to complete the "Final Forty"... these projects will use just over $\underline{\mathbf{2}}$ million tons of aggregate.

- Estimates courtesy of Dist. 3 Materials staff. 


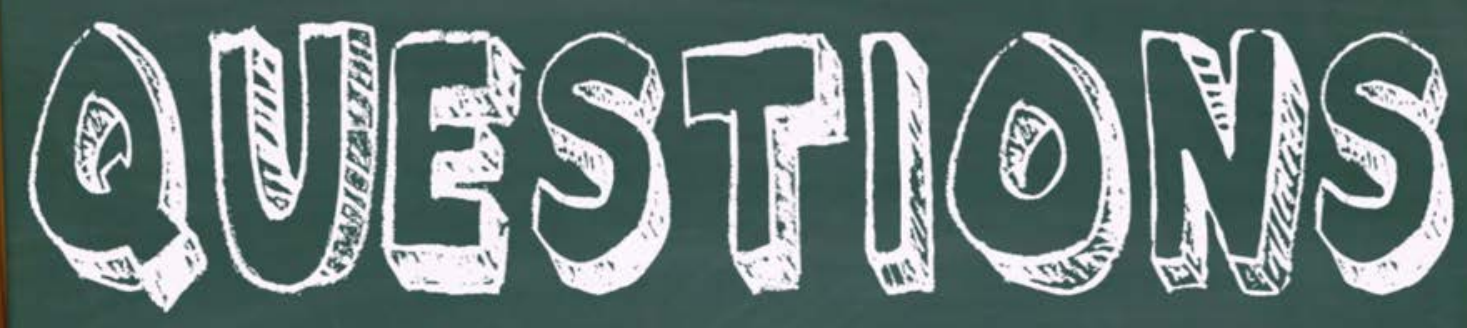

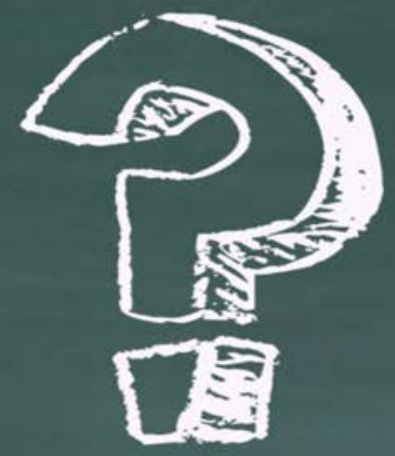

